\title{
HOMOPARENTALIDADE E ADOÇÃO: (RE) AFIRMANDO SEU LUGAR COMO FAMÍLIA ${ }^{1}$ \\ HOMOPARENTALIDAD Y ADOPCIÓN: (RE) AFIRMANDO SU LUGAR COMO UNA FAMILIA \\ HOMOPARENTHOOD AND ADOPTION: (RE)AFFIRMING ITS PLACE AS FAMILY \\ http://dx.doi.org/10.1590/1807-03102016v28n2p350 \\ Rosana Machin \\ Universidade de São Paulo, São Paulo/SP, Brasil
}

\section{RESUMO}

Ao longo da última década assiste-se no Brasil, bem como em outros países, a crescente demanda por adoção de crianças entre casais de mesmo sexo, fato que tem gerado na academia, mídia e sociedade civil, distintos posicionamentos sobre as especificidades deste vínculo parental e seus impactos psicológicos nas crianças e adolescentes. Nesse contexto apresentamos contribuições de uma pesquisa empírica com 12 casais de mesmo sexo (3 de mulheres e 9 de homens), realizada em São Paulo/Brasil, entre 2011 e 2012, incluindo casais com projeto de adoção e os que já tinham adotado. A análise do material revelou concepções de família e perspectivas de gênero, que subjazem às demandas formuladas pelos casais e os desejos e valores expressos por estes relativamente ao projeto de terem filhos. Na perspectiva desses casais, ter um filho é considerado um passo importante na afirmação de sua capacidade de constituir uma família.

Palavras-chave: adoção; família homoparental; homossexualidade; família; parentesco.

\section{RESUMEN}

Durante la última década estamos presenciando en Brasil y en otros países, la creciente demanda de adopciones entre parejas del mismo sexo, un hecho que ha generado en el mundo académico, medios de comunicación y la sociedad civil posiciones distintas sobre rasgos específicos de esta vínculo parental y su impacto psicológico en los niños y adolescentes. En este contexto se presenta las contribuciones de un estudio empírico de 12 parejas del mismo sexo (3 mujeres y 9 hombres), celebrada en São Paulo / Brasil, entre 2011 y 2012, incluyendo las parejas con proyecto de adopción ya aquellos que ya se habían adoptado. El análisis del material reveló concepciones de familia y perspectivas de género que subyacen a las demandas hechas por parejas y los deseos y los valores expresados por ellos en relación con el proyecto de tener hijos. Desde la perspectiva de estas parejas, tener un hijo se considera un paso importante en la afirmación de su capacidad para formar una familia.

Palabras clave: adopción; familia homoparental; homosexualidad; familia; parentesco.

\begin{abstract}
Throughout the last decade in Brazil (as well as in other countries) is possible to observe the increasing demand for the adoption of children by same sex couples. This fact has generated distinct views on the specificities of this kind of parental relationship and its psychological impacts in children and teenagers. In this context we present the contributions of an empirical research with 12 same sex couples ( 3 of women and 9 of men) held in Sao Paulo/Brazil, between 2011 and 2012, including couples with a prospect of adoption and those that already have adopted children. The material analysis revealed conceptions of family and gender perspectives, which underlie the demands formulated by the couples, as well as their wishes and values, expressed by the desire of having children. In these couples' perspective, having a child is considered an important step in the affirmation of their capacity of constitute a family.
\end{abstract}

Keywords: adoption; homoparenthood; homosexuality; family; kinship. 


\section{Introdução}

A emergência de configurações familiares formadas por pais/mães homossexuais acarreta novas demandas no campo social, cultural e legal e a necessidade de enfrentamento da temática em campos específicos de estudo como Sociologia, Antropologia, Direito e Psicologia. Contudo, apesar dessa situação, a literatura no país tem sido relativamente silenciosa em como esses casais constroem um projeto de parentalidade.

Como esse projeto é construído? Que modelo(s) de família casais de mulheres e homens desejam? Qual o papel reservado para a biogenética nele? Que critérios cercam suas escolhas e quais são as dificuldades experimentadas?

Parte da maior visibilidade de gays e lésbicas como pais e mães resulta de uma crescente aceitação pública para essa prática. Fazemos aqui uma distinção com as situações em que lésbicas e gays fundam famílias nas quais há filhos de relações heterossexuais prévias, de situações de estabelecimento de maternidade ou paternidade como pessoas solteiras e de criação de famílias por meio de autoinseminação por envolverem outras dinâmicas conforme destacado pela literatura (Dunne, 2000; Hayden, 1995; Haimes \& Weiner, 2000; Luce, 2010; Weston, 1991).

Sob a perspectiva da adoção no país, o Estatuto da Criança e do Adolescente, de 1990, em consonância com a Constituição Federal, já não restringia família à existência dos dois sexos como casal parental. No entanto, tornar explicita a orientação sexual correspondia, muitas vezes, a ter seu pedido de adoção negado na medida em que prevaleciam muitas resistências para efetivação desse direito. Pesavam nesse contexto as concepções de família presentes entre os operadores do direito e a importância dos laudos e pareceres de assistentes sociais e psicólogos forenses (Farias \& Maia, 2009; Farinelli \& Mendes, 2008; Uziel, 2007).

O estabelecimento de filiação conjunta por casais de mesmo sexo por meio do acesso às tecnologias reprodutivas $(\mathrm{TR})^{2}$ é prática relativamente recente no país e mesmo a adoção juridicamente oficializada com registro de dupla maternidade ou paternidade. É somente em 2013, que a norma médica que regulamenta o funcionamento da prática no país faculta o acesso de casais de mulheres e homens aos procedimentos (CFM, 2013).

Em maio de 2011, decisão do Supremo Tribunal Federal do Brasil, reconheceu a união estável entre pessoas do mesmo sexo permitindo a esses casais serem considerados uma unidade familiar como qualquer outra (STF, 2011).

O enfoque da pesquisa foram casais homossexuais masculinos e femininos buscando criar famílias por meio do uso de tecnologias reprodutivas e adoção. Nesse sentido, colocamos em perspectiva as escolhas dos sujeitos quanto às alternativas consideradas na construção do projeto de parentalidade estabelecendo um contraste entre os dois campos envolvidos (tecnologias reprodutivas e adoção), que podem configurar como solução para o estabelecimento de filiação. Neste texto enfocamos as narrativas que tomaram a adoção como escolha. Contudo, a análise empreendida está informada pelas fontes utilizadas na pesquisa maior. A pesquisa de campo foi realizada de 2011 a 2012, na Grande São Paulo e envolveu coleta de dados de fontes variadas como entrevistas semi-estruturadas com casais que buscavam construir um projeto de parentalidade, profissionais de saúde atuantes em serviços de reprodução assistida, consulta a bancos de sêmen no Brasil e exterior (Estados Unidos da América) e entrevistas com responsáveis por sua gestão, além da consulta a bibliografia de referência.

Vários têm sido os termos empregados para se referir às diversas configurações que articulam maternidade/paternidade e homossexualidade. Podese afirmar que não há consenso sobre o uso dos termos seja por organizações políticas e de apoio a direitos, seja no plano teórico ou entre as/os entrevistados/ as. Estudos ingleses e norte-americanos costumam empregar os termos, lesbian families, gay families, lesbian motherhood, same sex couples, lesbian and gay parenting/parenthood e non traditional families (Golombok et al., 2003; Luce, 2010, Mamo, 2007; Roudinesco, 2003; Weston, 1991). O termo homoparentalidade tem sido empregado traduzido do francês homoparentalité criado em 1996 pela APGL (Association des parentes et futurs parentes gays et lesbiens), sendo adotado por autores no Brasil (Grossi, 2003; Uziel, 2007; Zambrano, 2006;). Alguns autores observam que o uso do termo não é preciso já que permite se vincular o exercício da parentalidade com a orientação sexual (Farias \& Maia, 2009; Grossi, 2003; Roudinesco, 2003; Uziel, 2007) e, se por um lado, pode ter um caráter estratégico ao dar visibilidade ao tema, também pode acarretar distorções destacando uma diferença na capacidade de exercer a maternidade/ paternidade que não se sabe os efeitos que pode trazer. Outro termo que tem sido empregado, particularmente em referências do campo do Direito e da Medicina, é homoafetividade. Também registramos o uso dos termos famílias alternativas, maternidade lésbica e maternidade gay. Dado esse contexto empregamos 
nesse estudo os termos parentalidade, maternidade lésbica, parentalidade gay e homoparentalidade.

A questão de nomeação é um importante aspecto para destacarmos o quanto expressões de denominação remetem a classificações e definições parentais, situando um indivíduo numa determinada rede de relações e de categorias de pertencimento, ou seja, num sistema de parentesco. $\mathrm{O}$ emprego de expressões diversas para designar as parentalidades gays e lésbicas indica, que estas representam um desafio na criação de estratégias de composição ou de resistência ao modelo heteronormativo socialmente prevalente (Cadoret, 2012).

Salientamos que esse recorte visa iluminar essas "novas" configurações nas ideologias referentes à família, num país onde há a prevalência de um código relacional, fazendo da família um importante valor constituído por diversas formas de organização baseadas em princípios de reciprocidade e hierarquia relacionados a posições de classe e redes de parentesco, que se estendem para além do grupo consanguíneo (Fonseca, 2005; Machado, 2001).

A história compartilhada por estes casais fala de uma mudança cultural sobre os caminhos que estão sendo trilhados para se construir uma família por meio do acesso à biomedicina e aos processos de adoção. Os casos presentemente relatados, assim como aqueles reportados pela literatura (Hayden, 1995; Luce, 2010; Mamo, 2007; Tarnovski, 2012), revelam que as práticas de parentalidade entre casais de mesmo sexo envolvem mais valores do que aqueles específicos do casal implicando a consideração de diferentes alternativas para sua efetivação. Elas podem ser vistas igualmente como produto das distintas possibilidades institucionais da reprodução nesses contextos e assim se configuram como coprodutores dessas formas familiares, tais como, políticas públicas que facultam a adoção por estes casais ou reconhecem a família criada por esses laços quando do uso de TR, o acesso a serviços de saúde e poder implicar ambas as mulheres no projeto (uma pela gestação e a outra pelo fornecimento do óvulo para o processo), as possibilidades abertas pelos bancos de sêmen de escolha do doador e facultarem o uso desse material em uma nova gestação visando a consanguinidade entre irmãos (Fonseca, 2008).

O projeto de parentalidade entre homossexuais revelados pelos entrevistados(as) aponta para uma busca de autonomia e valorização do casal objetivando a escolha do melhor caminho para viabilizar esse desejo. Entre mulheres há predomínio da ideia de não envolver uma terceira pessoa no projeto de parentalidade, ou seja, incluir um doador conhecido que tenha pretensões de estar presente no desenvolvimento da criança. A adoção, no caso das mulheres, só é considerada quando a idade da que pretende gestar é um fato limitante para o uso de TR, quando há receio dos riscos que envolvem os procedimentos e quando os custos do tratamento não condizem com a situação financeira do casal. Nesse sentido, predomina entre as mulheres a busca ou uso de tecnologias reprodutivas. Entre homens não obtivemos casos de acesso às tecnologias reprodutivas, apesar de termos informações que isto está acontecendo no país. Mas, os entrevistados igualmente mencionam receios de buscar uma solução que os vincule e a criança também a uma provável genitora temendo que este vínculo possa colocar em risco o lugar de pais, ou mesmo, vir a significar a perda da criança para a mãe biológica num processo judicial futuro. Nesse sentido, optam em regra pela adoção legal de crianças. Entre os casais gays sobressai também a alegação pela preferência de que a criança tenha uma idade que permita a realização do cuidado pelo próprio casal (a partir de 3 anos), ou seja, não buscam bebês, bem como a referência à busca de estabelecimento de vínculo com a criança durante o processo de adoção.

A opção pela adoção é valorizada a partir da (re) consideração da importância do vínculo biológico/ consanguíneo e o desejo de fazer diferença na vida de muitas crianças que aguardam uma adoção considerando particularmente o contexto social do país.

\section{Metodologia}

Este texto está baseado em estudo qualitativo mais amplo que aborda as temáticas da adoção e das tecnologias reprodutivas na construção de configurações familiares entre homossexuais. A entrevista em profundidade foi utilizada como técnica de produção de dados empíricos e conduzida com casais de gays e lésbicas em São Paulo - Brasil, entre 2011 e $2012^{3}$. No recorte de análise aqui proposto utilizaremos os dados empíricos advindos das entrevistas com 12 casais de mesmo sexo ( 9 de homens e 3 de mulheres) incluindo casais com projeto de adoção (nove ao todo em elaboração ou já submetidos à justiça) e aqueles que já tinham adotado (dois casais gays e um de lésbicas). Somente um casal de lésbicas já possuía uma filha de um casamento heterossexual prévio. $\mathrm{O}$ objetivo do estudo foi investigar os tipos de demandas por adoção formuladas por estes casais e as concepções sobre família.

O uso dessa técnica possibilitou o resgate da dimensão simbólica e da subjetividade expressa nas 
falas dos entrevistados. Em outros termos, a partir da entrevista em profundidade foi possível captar sistemas de valores, crenças e normas que orientam e sustentam as escolhas dos sujeitos. As entrevistas, portanto, permitiram apreender a forma como esses sujeitos dão sentido às experiências vividas neste contexto na medida em que a fala de alguns pode, tal como sustenta Bourdieu, Chamboredon e Passeron (2004), ser representativa e informar maneiras de compreender, significar, perceber e agir de grupos sociais em determinados contextos históricos, sociais e culturais.

Os entrevistados foram localizados por meio do uso de contatos com comunidades LGBTT (Lésbicas, gays, bissexuais, travestis e transexuais) e redes de pessoas conhecidas da pesquisadora. Inicialmente, a ideia era fazer uso do método da bola de neve, contudo poucos casais entrevistados conheciam outros com planos similares de terem filho e também houveram alguns casais contatados que não aceitaram participar da pesquisa o que resultou num campo difícil e mais longo. Os entrevistados têm entre 28 e 50 anos de idade, são brancos com alto nível de escolaridade e representativos de camadas médias urbanas ${ }^{4}$.

As entrevistas seguiram um roteiro que abordou temáticas como a trajetória afetivo-sexual; concepções de gênero, família e reprodução; autonomia, independência e laços de família e parentesco; projeto de parentalidade e expectativas e vivências nesse processo de construção. Estas foram realizadas levando-se em conta os preceitos éticos da pesquisa, dentre os quais se destacam o caráter voluntário da participação, o anonimato e a confidencialidade das informações e mediante aprovação do Comitê de Ética em Pesquisa da universidade. As mesmas ocorreram em locais escolhidos pelos próprios entrevistados, no geral, em suas próprias residências. As entrevistas tiveram duração aproximada de uma hora e trinta minutos. Todas foram gravadas e posteriormente transcritas.

Os dados foram analisados considerando os seguintes procedimentos: leitura exaustiva de cada entrevista, estabelecimento de categorias temáticas, organização e análise do material segundo estas categorias e cotejamento dos conteúdos das categorias com a literatura existente sobre a temática geral e com as referências teóricas que nortearam a pesquisa. Levantamento junto a sites no Brasil, no Reino Unido e Estados Unidos da América foram realizados no tocante aos contextos legais e técnico-científicos relacionados às práticas do campo.

\section{Discussão}

\section{Família e homoparentalidade}

Há no Brasil a prevalência de um código relacional fazendo da família um valor que perpassa toda a sociedade, sendo constituído de diversidade de formas de organização (em toda a história colonial, moderna e contemporânea) baseadas em princípios de reciprocidade e hierarquia relacionados a posições de classe (Machado, 2001) e gênero. Assim, família é uma noção que varia conforme a categoria social com que lidamos e se baseia no estabelecimento de dinâmicas e redes de parentesco que se estendem para além do grupo familiar e da unidade doméstica (Fonseca, 2005). Nesse contexto, o valor da família para as camadas populares está centrado particularmente no princípio de reciprocidade, solidariedade e de obrigações entre integrantes de toda a família e da parentela sobre os indivíduos e se ancora nas atividades domésticas do dia-a-dia e nas redes de ajuda mútua; entre as camadas médias prevalecem valores mais individualistas e menos dependentes do valor englobante da família (família nuclear) identificada com a modernidade e altamodernidade; entre a elite a família prevalece como linhagem (expressando orgulho de seu patrimônio) e institui um exercício privilegiado de recursos entre integrantes da parentela, que se transformam em capital social, político e econômico, mantendo um espírito corporativista (Fonseca, 2005; Machado, 2001).

Os códigos relacional e individualista coexistem e, nesse sentido, podem se articular ou se destacar segundo posições de classe expressando o contexto da sociedade brasileira marcada ainda por desigualdades e por direitos de cidadania igualitária e individual não amplamente generalizados (Machado, 2001). É a partir dessa matriz que podemos considerar a pluralidade de arranjos familiares e o sentido atribuído à família num contexto de crescente expansão do individualismo e de valores associados a "escolha" e "opção" no mundo ocidental. Nesse sentido, se situa a crescente visibilidade de novas configurações familiares até há pouco tempo marginalizadas, pois decorrentes da conjugalidade homossexual e da luta para o seu reconhecimento civil ${ }^{5}$.

A filiação é compreendida como uma construção social legitimada pelo Direito e a adoção se configura como um meio de favorecer a inserção de uma criança em uma dada entidade familiar considerando a importância do seu desenvolvimento, o abandono 
desta pelos genitores e o interesse de um adulto na parentalidade (Uziel, 2007). A biologia, nesse sentido, não configura fonte única de estabelecimento de filiação.

O processo de transformações políticas, culturais e legislativas em torno da descriminalização da homossexualidade, da igualdade de acesso por casais de mesmo sexo ao casamento civil e a reivindicação pelo reconhecimento da adoção de crianças por casais de mesmo sexo (e de registro civil de dois pais ou duas mães em crianças oriundas de famílias homoparentais) em curso, nas últimas décadas, em diferentes sociedades foi gerado por mudanças de paradigmas e de mentalidades que tem como importante referência a luta pelo reconhecimento de igualdade de direitos dos grupos LGBTT. Assim, o desejo por filiação não se separa do contexto social, cultural e econômico que emerge e que igualmente está revestido de dimensão política e subjetiva (Herbrand, 2009; Tarnovski, 2012). Na análise de Almeida (2010) sobre este tema em Portugal, Espanha e EUA sobressai a referência ao princípio de igualdade de direitos dos cidadãos, sendo o direito à igualdade mais relevante do que os supostos elogios à "diferença".

\section{A elaboração do projeto}

Importa considerar que a decisão dos casais para realizar o projeto de ter filhos está informada por um contexto no qual estão em jogo valores culturais e simbólicos associados ao ideal de conformação de uma "verdadeira" família. Nesse sentido, são referidos valores sobre concepção de família, sangue e transmissão genética. Entre operadores do direito sobressai a ideia de que nos processos envolvidos na adoção se procura uma família para uma criança, ao passo em que nas tecnologias reprodutivas se procura um filho para um casal (Ramírez-Gálvez, 2011). Na adoção falamos de um campo baseado na intervenção realizada pelo Estado, mediada por instituições, operadores do direito (advogados, juízes), assistentes sociais e psicólogos jurídicos, que analisam e decidem a qualificação de casais ou pessoas solteiras para a adoção. $\mathrm{Na}$ reprodução assistida as demandas são formuladas, em regra, às clínicas privadas no âmbito do consumo de serviços médicos visando à obtenção de uma gestação (Machin, 2000; 2003). Essa distinção se faz importante, sobretudo, porque referências ao modelo biológico de reprodução marcam o processo de busca pelo filho adotivo como se verá adiante (Fonseca, 1995; Costa, 1988).

Nos relatos referentes ao projeto de parentalidade entre casais gays e lésbicas, o desejo por filhos pode ser algo vinculado à experiência de um ou ambos os adultos envolvidos no casal. Entre gays há menção a criança como um desejo de adultos individualmente, que foi se efetivar posteriormente como um projeto de casal. Entre lésbicas o projeto foi expresso claramente como um desejo do casal. Essa situação guarda relação com achados de Gross (2009) relativos ao projeto de parentalidade entre lésbicas e gays na França. E, nesse sentido, enquanto a busca parental entre lésbicas pode aproximá-las da vivência de outras mulheres nãolésbicas ('uma mulher como outras') entre os gays a busca pela paternidade não os insere num contexto de proximidade 'como outros homens', mas tende a sugerir um lugar de monstruosidade ou pedofilia (Gross, 2009).

Podemos efetivamente considerar o peso de representações de gênero nas diferentes articulações com relação a parentalidade e a conjugalidade e ideias relativas a valores biológicos e não biológicos relacionados a ser pai e mãe (Gross, 2009). E, igualmente, o peso atribuído às suas histórias familiares prévias na conformação do modelo de família que buscam construir. Apenas um dos homens entrevistados referiu que o desejo de ser pai não tinha passado pela sua cabeça. Assim, as narrativas foram fortemente atreladas à própria história pessoal e à família de origem. Referências à infância, ao nascimento e ao cuidado de primos e sobrinhos no convívio familiar foram explicitadas e tomadas como indícios de uma afinidade eletiva com a paternidade.

$\mathrm{Na}$ realidade assim, eu cresci numa família muito próxima, muito ... minha relação familiar é muito boa, muito próxima, a gente tá sempre junto. Eu com as minhas irmãs, com meus sobrinhos, com a minha mãe, meu pai na época e ... então pra mim, sempre foi muito intrínseco isso, entendeu? Da realização e continuação dessa família. [R]

Os casais gays, de forma bastante espontânea ${ }^{6}$, afirmaram não se encaixar na "cultura gay". Cultura esta que aparece, nos relatos, como bastante estereotipada e associada à promiscuidade, o que se contrapõe à família que eles afirmam que tiveram como referência e padrão que buscam atualizar na relação atual. Como observa Butler (1998), categorias de identidade não se expressam unicamente pela descrição, mas são sempre normativas, delimitando processos de inclusão e exclusão. Ou seja, se identificar com a cultura gay implica para esses casais estar associado com estereótipos dos quais querem se afastar ao buscarem construir uma família. Construção de identidades correspondem a um processo que opera pelo estabelecimento de semelhanças e diferenças, nós - eles (Woodward, 2005). Meinerz (2011) em etnografia produzida sobre relações homoeróticas 
femininas em segmentos médios urbanos na cidade de Porto Alegre observa, que o lugar do gueto entendido como um agrupamento entre sujeitos envolvidos no universo homossexual (prática sexual e também existencial) e, portanto, relacionado a modos de vida e construção de subjetividades reflete ao mesmo tempo uma lógica de exclusão social e de proteção. Entre grupos médios urbanos, mais marcados pela perspectiva da individualidade e vivendo situações de maior aceitação social por parte de suas famílias, haveria menor busca de apoio na comunidade homossexual para a construção de pertencimento e equilíbrio afetivo. Sobressai a busca de sociabilidade fora da "cultura gay" na perspectiva do direito de frequentar qualquer lugar e vivenciar em seu círculo de relações presença de outros indivíduos (leia-se heterossexuais).

O processo da decisão de ter filhos se configurou a partir das trajetórias individuais (em relacionamentos prévios, alguns heterossexuais) e, especialmente, na relação em que estão hoje. Relação considerada como 'padrão', 'tradicional' no sentido dos vínculos de reciprocidade, conjugalidade e de regras de fidelidade. Esta referência, que todos fizeram questão de frisar, está no discurso de quem já concretizou a adoção e de quem ainda não a concretizou.

O reconhecimento da relação de casal propicia a busca pelo projeto de parentalidade como uma etapa importante de se afirmar como família. Este costuma estar associado com a compreensão de que se atingiu uma meta de estabilidade profissional e financeira, num modelo de família presente em camadas médias (Fonseca, 2006; Machin, 2000; Ramírez-Gálvez, 2011). Assim, aspectos materiais como compra de casas e apartamentos maiores ou reformas pensando no(s) filho(s), poupança para gastos futuros com educação, entre outros, são relatados como importantes passos ligados à decisão de adotar. A referência à mídia e às redes sociais próximas no sentido de apresentar situações exitosas de casais (gays e lésbicas) com filhos, em termos das conquistas legais de adoção, bem como nos termos de aceitação social igualmente foram mencionadas como um estímulo ou encorajamento para a construção e discussão do projeto de parentalidade entre os casais.

E também nós ao longo do tempo descobrimos, encontramos casais, pessoas gays que tinham filhos, outras experiências. Mudaram um pouco as possibilidades. E ai a gente começou a falar ... Acho que quando essa possibilidade surgiu ficou claro para cada um de nós que nós poderíamos ter filhos. [P]

Embora o plano de adoção possa ser partilhado com as famílias de origem, algumas vezes com embates pela não aceitação de pais e mães ou descrédito em termos da possibilidade de sucesso, o processo de adoção se apresenta como próprio ao casal e pouco compartilhado com a família.

Então, minha família já assistiu essas duas tentativas de adoção minha, né? Hoje, assim, minha família ... Assim, sabem a intenção eu quero ser mãe, né? Que eu tenho a intenção de adotar, mas a gente num, num tocou mais no assunto assim. [A]

\section{Rompendo com a "vaidade genética"}

Os caminhos percorridos pelos casais gays até chegarem à decisão de adotar parecem, à primeira vista, mais restritos do que entre as mulheres, sobretudo porque a possibilidade de recorrer as TR (à época das entrevistas) não estava regulamentada no país. Entretanto, não seria correto afirmar que para eles o imaginário do filho biológico não está presente. A consanguinidade e o desejo de 'se ver na carinha do bebê e ter um filho geneticamente aparentado' também apareceram nos discursos de alguns casais gays. Mas, as referências à utilização das TR sobressaíram como algo hipotético.

Depois eu cheguei até a pensar ... Eu tenho uma irmã. Ela tem vinte e poucos anos. Não, né? Eu falei: Pô, a Gabi podia gerar um filho seu, né, geneticamente seu. Eu não poderia porque é minha irmã, mas poderia gerar um filho, pô. Ia ser tão mais fácil os trâmites jurídicos. $[\mathrm{F}]$

Os estudos sobre adoção têm reportado o quanto a busca e o perfil desejado do filho adotivo se inscreve, na maioria das vezes, a partir de princípios relativos ao modelo biológico de reprodução (Costa, 1988; Fonseca, 2009; Marre \& Bestard, 2004; RamíresGálvez, 2011). Nesse contexto, há preferência por uma criança recém-nascida e com biótipo similar aos pais adotivos. Essa aproximação é mobilizada visando neutralizar a carga genética diferente dos pais biológicos, como um artifício para diminuir o tempo de exposição da criança a uma dada sociabilidade, que se supõe negativa (pela institucionalização, abandono ou mesmo condições de vida difícil). Há uma preocupação com as características que a criança possa ter herdado dos pais biológicos. Essa visão está articulada com a compreensão contemporânea, que confere cada vez mais peso à genética que se herda. "Eu também tenho essa vontade genética. Eu chamo de vaidade genética, porque eu queria ver um serzinho que tem as minhas características, sei lá" [F].

No entanto, a busca por adoção entre casais gays foge desse contexto de aproximação ao modelo biológico. Nos processos de reflexão esse filho 
geneticamente aparentado chega a ser tomado como uma atitude 'egoísta' ou de 'vaidade genética', como no caso de $[\mathrm{F}]$ e $[\mathrm{E}]$. "Eu diria assim: o desejo de ter um filho geneticamente meu é quase egoísta. Quando eu penso numa adoção eu saio um pouco só do meu desejo e penso também no outro" [E].

Outras dimensões são destacadas entre casais gays valorizando a adoção como um ato social, especialmente, entre os casais que já efetivaram a adoção. Contudo, as falas de "conveniência" (há crianças para serem adotadas e os casais gays querem adotar crianças) igualmente ganham destaque.

Tem um desejo de criar a criança de um lado, e ficou bem claro, por exemplo, com o [companheiro], que tem essas crianças, que tem o desejo de ter uma família. Então vamos fazer com que esses desejos se encontrem e vamos para frente, só isso. [P]

Entre lésbicas a busca por um adotado recémnascido é prevalente. A adoção tardia, de crianças mais velhas (valorizada pelos casais de homens ${ }^{7}$ ), não é considerada como opção para as mulheres, que desejam vivenciar o cuidado de bebês. No caso de casais gays esse cuidado é inclusive visto como algo que pode representar dependência de cuidadoras e, portanto, implicar uma menor autonomia do casal no processo. Assim, entre os homens a ética do cuidado é bastante valorizada.

Não se identifica nas narrativas referências a prevalência de um dado perfil de adotado com relação a sexo ou mesmo cor/etnia. Não há intenção de buscar uma criança com características fenotípicas similares aos demandantes. Essa posição encontra similar entre os estudos relativos à adoção internacional entre lésbicas e gays, que revelam haver entre estes casais maior abertura para adoções de crianças distintas de suas características étnicas/raciais (across racial lines), portadoras de problemas de saúde ou mesmo necessidades especiais (Brodzinsky \& Pertman, 2012; Faar \& Patterson, 2009).

A opção pela adoção legal e seu correspondente segredo (justiça) que implica a premissa de sigilo total quanto às famílias de origem é algo valorizado ${ }^{8}$. Pesa sobre arranjos como o da adoção à brasileira ${ }^{9}$ (Fonseca, 1995) receios relativos à proximidade com a mãe de nascimento ${ }^{10}$. Casais de homens e de mulheres são bastante enfáticos no posicionamento pela adoção legal, sendo que dentre os dois casais que concluíram o processo de adoção (juntos há 19 e 26 anos) a decisão por esta escolha é pontuada como a mais acertada pelo fato de não envolver riscos de futuras disputas judiciais com a mãe biológica e, igualmente, por possibilitar que o filho tenha em seu registro civil os nomes dos dois pais. O "[M] é filho dos dois: é filho de dois pais. Ele tem toda essa documentação. Nós somos casados. Hoje, legalmente, a gente tem uma vida familiar absolutamente estabelecida".

O segredo de justiça na adoção impedindo o acesso à informação relativo às famílias de origem passou a ser visto como algo necessário e consensual objetivando promover o bem-estar dos adotados. No Brasil o adotado tem direito a conhecer sua origem biológica após completar 18 (dezoito) anos por meio do acesso à Justiça (Fonseca, 2010). Fonseca (2009) observa que chavear os arquivos tornando-os somente passíveis de abertura pela requisição à justiça está ligado aos estereótipos negativos construídos sobre a mãe de nascimento (como abandonante), ao medo da "concorrência" pelo afeto da criança e em buscar imitar o "natural", consanguíneo. Assim, a adoção figuraria "como se" aquela criança tivesse nascido naquela família. A autora também chama a atenção para as tensões correspondentes a essa definição presente no campo da adoção, na medida em que há desigualdades sociais e políticas entre os adotantes e aqueles que conduziram seus filhos para adoção. Para a mãe de nascimento uma adoção à brasileira permitiria desempenhar um papel relativo na escolha da família em que o filho vai ficar como igualmente acompanhar de longe sua vida. Com a presença efetiva do Estado e a perspectiva legal conduzindo o processo de adoção as famílias de nascimento são alijadas do processo. Importante considerar que tem crescido entre adotados e mesmo entre filhos concebidos por meio de tecnologias reprodutivas à busca pelo direito às suas histórias pessoais colocando em questão esse argumento (Fonseca, 2006; Golombok et al., 2003).

\section{Trajetórias no processo de adoção}

A decisão pela adoção envolve o reconhecimento e a familiarização com os trâmites jurídicos, processo que é considerado como difícil, moroso e incerto, para os que de fato percorreram o percurso e para os que ainda estão no processo ou avaliando o momento mais apropriado para dar início ao mesmo. Entre os dois casais que concretizaram o processo há similitudes e diferenças. Em termos de similitudes, ambos acabaram por adotar criança do sexo masculino e os filhos adotivos têm o nome dos dois pais na sua certidão. As diferenças, por seu turno, dizem respeito à vivência do processo.

Na visão de $[R]$ o processo foi descrito como difícil. "O processo todo, como foi um processo longo, dificultoso. Agente só ganhou lá, no Tribunal de Justiça. Foi-nos negado várias vezes e a gente sabia que a gente queria ele, então a gente foi lá brigar". No contexto de 
um relacionamento estável há cerca de 10 anos, o casal é apresentado a um abrigo de uma cidade litorânea de São Paulo por uma das irmãs. A descrição da chegada ao abrigo é carregada de detalhes e sentimentos. Para eles, foi amor à primeira vista. A criança tinha um ano e um mês. A partir deste encontro, ambos decidiram 'lutar' pela criança, processo que durou dez meses.

Eu não sei nem qual é a situação dessa criança, mas esse é o nosso filho. Agora a gente vai atrás. Ele não estava pronto pra adoção. Ele não tinha nem sido destituído ainda. Tinha sido abandonado. E ai a gente brigou por isso ... Ai a gente entrou com a ação. Ela foi negada pela promotoria: o promotor foi contra e o juiz, três meses depois deu uma sentença dizendo que nós éramos imaturos para sermos pais. Eu com quase quarenta anos de idade, ele com quarenta e três anos de idade: imaturos. Então, ou seja, um baita de um preconceito disfarçado, que eles não tinham coragem de colocar isso no papel. Recorremos. Fomos para o Tribunal de Justiça. Nós já estávamos há seis meses frequentando o abrigo todo final de semana, [nome da criança] já me chamava de papai ... Só que ele (Juiz) tinha tanta convicção que nós éramos imaturos que ele proibiu a nossa entrada no abrigo ... Para que se quebrasse o vínculo. E quando ele colocou isso no papel, foi nosso grande trunfo, porque ele escreveu que já existia um vínculo. Entramos no TJ, brigamos, brigamos e perdemos ... Por obra de Deus ou do destino, esse homem que estava julgando o nosso caso, disse que teria que ir para o exterior ... E no retorno ele veria o que ele acharia disso ... esse homem pegou uma infecção lá, ficou em coma e quase morreu. E ai todo o grupo julgador foi trocado. Marcaram uma nova audiência. Nós fomos com nossos advogados e ai nós ganhamos por unanimidade. Eles diziam que desse essa criança; que se entregue essa criança de imediato a esses pais... Os jovens foram os que nos cortaram e os mais velhos diziam que por experiência de vida, eles sabiam que o que valia era o amor. [R]

Nos caminhos da adoção dos casais que participaram da pesquisa a ideia de 'frequentar um orfanato' e estabelecer um vínculo com a criança durante o processo de adoção é valorizada. Nesse sentido, a força do sangue ou o "vazio do sangue" é substituído por um outro registro - o de um encontro predestinado, místico, em que forças do universo conspirariam para proporcionar o vínculo (RamírezGálvez, 2011).

Eu acho que o fundamental, quem tá adotando, é ter esse encontro, esse encontro de almas, como a gente teve com $o$ [nome da criança]. Eu tive assim ... A primeira vez que eu fui no abrigo e olhei pro [nome da criança], assim, e ele me olhou, assim, com um ano e quatro meses, ele ... Nossa, ele me deu um abraço tão forte pra um bebê, assim ... Naquele momento eu tive a certeza: assim, ele é nosso filho mesmo. [E]
[J] tem 50 anos e foi transferido para o Brasil pela empresa que trabalha, há quatro anos, sendo acompanhado pelo seu companheiro [P]. O casal, após se instalar na cidade, decide entrar com um processo de adoção já que para eles os trâmites jurídicos aqui seriam mais fáceis, pois seu país de origem não faculta a adoção por homossexuais. Eles decidiram por adoção de criança mais velha para, segundo eles, terem as chances aumentadas pela não 'concorrência' com o padrão de adoção brasileiro (meninas, brancas e bebês):

Já fomos avisados que como estrangeiros a gente não tinha prioridade sobre os brasileiros. E como os brasileiros sempre querem bebês ... Então nós fomos informados que tinha crianças de 2, 3 e 4 anos ... que do ponto de vista dos pais brasileiros já eram velhos demais para serem adotados. E aí a gente pensou ...já não somos tão jovens, uma primeira coisa. Segunda coisa, a gente ... nossa experiência com crianças era que para construir um vínculo com uma pessoa você não precisa conhecer essa pessoa desde a infância, como bebê. Também eu acho que como homens a gente não sentia essa necessidade de ter uma relação com um bebê. [P]

Os casais que optaram pela adoção, mas ainda não a concretizaram, consideram que as recentes conquistas no plano jurídico favorecendo os casais homossexuais trazem boas perspectivas de sucesso. Assim, há menção "E até a alternativa de adoção aumentou bastante por conta até desse casal, que eles conseguiram fazer a adoção no nome dos dois" [F].

\section{Considerações finais}

$\mathrm{Na}$ época moderna, a família foi se dessacralizando dos sentidos que historicamente a constituíram relativos à transmissão de patrimônio, de espaço onde impera uma lógica afetiva baseada no amor romântico e na exclusividade sexual por meio do casamento e na divisão de trabalho entre os esposos com os encargos de formação educacional dos filhos baseados na autoridade. Perdido o lugar da "aura divina" a família se encontra em reformulação, mas não deixa, paradoxalmente, de ser considerada como uma instituição importante e desejada (Roudinesco, 2003).

Pode-se afirmar que tem havido uma releitura do parentesco consanguíneo na sociedade ocidental contemporânea, em razão da valorização de vínculos afetivos, construídos pormeio de afeição mútua escolha, em detrimento dos vínculos estabelecidos pelos "fatos da biologia". Princípios constituintes da modernidade como autonomia, independência e diminuição da 
importância dos laços de parentesco figuram nos novos arranjos familiares em constituição. Nas narrativas produzidas nesse estudo sobre o desejo de ter filhos, sobressai um projeto conjunto que vincula a história pessoal com o interesse pela maternidade/paternidade. Ter um filho é visto como um importante passo no reconhecimento e afirmação da família construída, inclusive possibilitando uma (re) aproximação com suas famílias de origem, quando a descoberta da sexualidade teria provocado afastamentos.

As narrativas revelam que a adoção legal prevalece como escolha baseada na importância do reconhecimento legal das famílias e do bem-estar da criança acolhida. Manifestam igualmente receio de que a opção por outros arranjos utilizados para viabilizar a chegada de um filho possa criar vulnerabilidades para o casal e a criança, por temerem que a força dos laços biológicos se sobreponha ao vínculo social ou dispositivo legal. No discurso dos casais sobressai a percepção da adoção como um compromisso social. Nesse sentido, é importante destacar que os casais (gays e lésbicas) entrevistados buscam crianças para adoção fora dos perfis mais demandados no país, demonstrando maior abertura pela acolhida de crianças com perfil fenotípico distintos dos integrantes do casal (em particular, quanto à etnia/raça), portadoras de necessidades especiais ou com problemas de saúde. Esta situação guarda correspondência com a literatura internacional sobre tema.

Finalmente, como observa Almeida (2009), se a dinâmica parental presente em arranjos lésbicos e gays guarda ainda os efeitos hegemônicos presentes na ordem de gênero e na ordem heteronormativa que lhe subjaz, igualmente desafia modelos de gênero e de relações parentais.

\section{Notas}

1 Este estudo contou com financiamento do CNPq (Conselho Nacional de Desenvolvimento Científico e Tecnológico) por meio de auxílio à pesquisa e bolsa de pós-doutoramento e foi apresentado no IX Congresso Ibero Americano de Psicologia, realizado em Lisboa em setembro de 2014.

2 Tecnologias reprodutivas designam algumas tecnologias médicas incluindo, por exemplo, estimulação da ovulação, fertilização in vitro (FIV), inseminação com doador (ID), injeção intracitoplasmática de espermatozóide (ICSI) e são usadas para obter a gestação em contextos nos quais ela não pode ser obtida por relações sexuais. Similarmente o termo reprodução assistida (RA) é usado.

3 Uso o termo gays e lésbicas considerando seu sentido de identidade visando caracterizar homens e mulheres e suas experiências de sexualidade, gênero e reprodução. Reconheço que o termo compreende diferentes concepções e subjetividades, que são construídas em processos históricos e sistemas de conhecimento (Mamo, 2007).
4 O perfil homogêneo das entrevistas não caracteriza uma situação buscada, mas resulta de particularidade do campo.

5 Segundo Tarnovski(2004), no Brasiléosistema deparentesco que funciona como suporte da identidade social dos casais homossexuais com filhos no acesso e reconhecimento à família e não uma busca de reconhecimento e afirmação do ser lésbica/gay.

6 Já que este não era um tópico específico do roteiro de entrevistas.

7 Os dois casais que concretizaram adoções adotaram meninos em torno dos 3, 4 anos.

8 A adoção plena e premissa do sigilo total emerge nos Estados Unidos (EUA) somente em torno de 1960, quando a adoção foi baseada numa réplica da reprodução biológica. Nesse sentido, era importante afastar a memória dos pais biológicos. A esse respeito Fonseca (2009).

9 Adoção à brasileira corresponde à prática ilegal de registrar um filho como próprio, omitindo os nomes de seus verdadeiros pais biológicos.

10 Fonseca menciona estudo realizado no Paraná com 400 famílias adotivas e revela que pais de classe média tendem a optar pela adoção legal enquanto pobres preferem adoção à brasileira (2006).

\section{Referências}

Almeida, M. V. (2009). O esperma sagrado. Algumas ambiguidades da homoparentalidade em contextos euroamericanos contemporâneos. Quaderns, 25, 109-121.

Almeida, M. V. (2010). A chave do armário. Homossexualidade, casamento, família. Florianópolis: Editora UFSC.

Bourdieu, P., Chamboredon, J. C., \& Passeron, J. C. (2004). O oficio de sociólogo. Metodologia da pesquisa na Sociologia. Petrópolis, RJ: Vozes.

Brodzinsky, D. \& Pertman, A. (2012). Adoption by lesbian and gay men. A new dimension in family diversity. Oxford: Oxford University Press.

Butler, J. (1998). Fundamentos contingentes: o feminismo e a questão do pós-modernismo. Cadernos Pagu, 11, 11-42.

Cadoret, A. (2012). Famílias homoparentales: la clave del debate. Nuevas formas de família. Metropolis. Revista de Informació y pensamiento urbanos. Acesso em 09 de abril, 2015, em http://w2.bcn.cat/bcnmetropolis/arxiu/es/ page0b0e 2.html?id=23\&ui $=609$

Conselho Federal de Medicina - CFM. (2013). Resolução $n^{\circ}$ 2.013/2013. Brasília, DF: Autor. Acesso em 09 de abril, 2015, em http://www.portalmedico.org.br/resolucoes/ CFM/2013/2013 2013.pdf

Costa, M. C. S. (1988). Os "Filhos do Coração": Adoção em Camadas Médias Brasileiras. Tese de Doutorado, Programa de Pós-Graduação em Antropologia Social, Museu Nacional, Universidade Federal do Rio de Janeiro, RJ.

Dunne, G. A. (2000). Opting into motherhood: lesbians blurring the boundaries and transforming the meaning of parenthood and kinship. Gender \& Society, 14(1), 11-35.

Farias, M. O.\& Maia,A.C. B. (2009). Adoção por homossexuais: a familia homoparental sob o olhar da Psicologia Jurídica. Curitiba: Juruá Editora.

Farinelli, M. R. \& Mendes, S. L. M. (2008). Adoção por homoafetivos. Serviço Social e Realidade. 17(1), 182-196.

Farr, R. H. \& Patterson, C. J. (2009). Transracial adoption by lesbian, gay and heterosexual couples: who completes 
transracial adoptions and with what results? Adoption Quaterly, 12, 187-204.

Fonseca, C. (1995). Caminhos da adoção. São Paulo: Cortez.

Fonseca, C. (2005). Concepções de família e práticas de intervenção: uma contribuição antropológica. Saúde $e$ Sociedade, 14(2), 50-59.

Fonseca, C. (2006). Da circulação de crianças à adoção internacional: questões de pertencimento e posse. Cadernos Pagu, 26, 11-43.

Fonseca, C. (2008). Homoparentalidade: novas luzes sobre o parentesco. Estudos Feministas, 16(3), 1-8.

Fonseca, C. (2009). Abandono, adoção e anonimato: questões de moralidade materna suscitadas pelas propostas legais de "parto anônimo". Sexualidad, Salud y Sociedade, 1, 30-62.

Fonseca, C. (2010). O direito às origens: segredo e desigualdade no controle de informações sobre a identidade pessoal. Revista de Antropologia, 53(2), 493-526.

Golombok, S., Perry, B., Burston, A., Murray, C., MooneySomers, J., Stevens, M., \& Golding, J. (2003). Children with lesbian parents: a community study. Developmental Psychology, 39(1), 20-33.

Gross, M. (2009). The desire for parenthood among lesbians and gay men. In D. Marre \& L. Briggs (Orgs.), International Adoption. Global Inequalities and the Circulation of Children (pp. 87-102). New York; London: New York University Press.

Grossi, M. P. (2003). Gênero e parentesco: famílias gays e lésbicas no Brasil. Cadernos Pagu, 21, 261-280.

Haimes, E. \& Weiner, K. (2000). 'Everybody's got a dad...' Issues for lesbian families in the management of donor insemination". Sociology of Health \& Ilness. 22(4), 477-499.

Hayden, C. (1995). Gender, genetics and generation: reformulating biology in lesbian kinship. Cultural Anthropologie, 10(1), 41-63.

Herbrand, C. (2009). Déclinasions du désir d'enfant dans les coparentalités homosexuelles. Revue des Sciences Sociales, $41,42-51$.

Luce, J. (2010). Beyond expectation: lesbian/Bi/queer women and assisted reproduction. Toronto: University of Toronto Press.

Machado, L. Z. (2001). Famílias e individualismo: tendências contemporâneas no Brasil. Interface, 5 (8), 11-26.

Machin, R. (2000). Relações de gênero, infertilidade e novas tecnologias reprodutivas. Estudos Feministas, 8(1), 212-228.

Machin, R. (2003). Novas tecnologias reprodutivas conceptivas: produzindo classes distintas de mulheres? In M. Grossi, M. Tambelini, \& R. Porto (Orgs.), Novas tecnologias reprodutivas conceptivas: questões e desafios (pp. 41-49). Florianópolis: Letras Livres.

Mamo, L. (2007). Queering reproduction: achieving pregnancy in the age of technoscience. Durham \& London: Duke University Press.

Marre, D. \& Bestard, J. (2004). "Sobre la adopción y otras formas de constituir famílias: a modo de introducción". In D. Marre \& J. Bestard (Orgs.), La adopción y el acogimiento: presente y perspectivas (pp. 17-71). Barcelona: Universitat de Barcelona.

Meinerz, N. E. (2011). Etnografia sobre relações homoeróticas femininas em segmentos médios urbanos na cidade de Porto Alegre. Rio de Janeiro: Editora UERJ.

Ramírez-Gálvez, M. (2011). Inscrito nos genes ou escrito nas estrelas? Adoção de crianças e uso de reprodução assistida. Revista de Antropologia, 54(1), 47-87.
Roudinesco, E. (2003). A família em desordem. Rio de Janeiro: Jorge Zahar.

Supremo Tribunal Federal - STF. (2011). Supremo reconhece união homoafetiva. Acesso em 14 de dezembro, 2015, em http://www.stf.jus.br/portal/cms/verNoticiaDetalhe. asp?idConteudo=178931. Tarnovski, F. L. (2004). "Pai é tudo igual?": significados da paternidade para homens que se autodefinem como homossexuais. In A. Piscitelli, M. F. Gregori, \& S. Carrara (Orgs.) Sexualidade e saberes: convenções e fronteiras (pp. 385-414). Rio de Janeiro: Garamond.

Tarnovski, F. L. (2012). Devenir père homosexuel en France: la construction sociale du désir d'enfant. Etnográfica, 16(2), 247-267.

Uziel, A. P. (2007). Homossexualidade e adoção. Rio de Janeiro: Garamond.

Weston, K. (1991). Families we choose: lesbian, gays, kinship. New York: Columbia University Press.

Woodward, K. (2005). Identidade e diferença: uma introdução teórica e conceitual. In T. T. Silva (Org.), Identidade $e$ diferença: a perspectiva dos estudos culturais (pp. 7-72). Petrópolis, RJ: Vozes.

Zambrano, E. (2006). Parentalidades “impensáveis": pais/ mães homossexuais, travestis e transexuais. Horizontes Antropológicos, 12(26), 123-147.

\section{Agradecimento}

Este estudo contou com financiamento do Conselho Nacional de Desenvolvimento Científico e Tecnológico - CNPq, Edital MCT/CNPq 14/2010 Universal Processo $n^{\circ} .483081 / 2010-8$, por meio de auxílio à pesquisa e bolsa de pós-doutoramento e foi apresentado no IX Congresso Ibero Americano de Psicologia, realizado em Lisboa em setembro de 2014.

Submissão em 09/04/2015

Revisão em 05/08/2015

Aceite em 17/08/2015

Rosana Machin é doutora e professora do Departamento de Medicina Preventiva, Faculdade de Medicina na Universidade de São Paulo. Endereço para correspondência: Faculdade de Medicina da USP, Departamento de Medicina Preventiva, Avenida Dr. Arnaldo, 455/sala 2221, São Paulo/SP, Brasil.

CEP 01246-903.

E-mail: $\underline{\text { rmachin@,usp.br }}$ 